Gut, 1962, 3, 167

\title{
Peripheral ligation of the hepatic artery during surgery in non-cirrhotic patients
}

\author{
M. ANDREASSEN, J. LINDENBERG, AND K. WINKLER \\ From the Departments of Surgery $D$ and of Medicine B, Rigshospitalet, \\ University of Copenhagen, Denmark
}

EDITORIAL SYNOPSIS A report is given on four non-cirrhotic patients in whom the hepatic artery proper was ligated for different reasons. In the post-operative course only slight signs of liver damage were present and no later sequels were observed.

Ligation of the hepatic artery central or distal to the point of origin of the gastroduodenal tributary has for several years been used in the treatment of patients with cirrhosis of the liver. On the other hand it has so far been generally accepted that ligation of the hepatic artery in patients with a normal liver is followed by serious complications, especially if the hepatic artery is tied peripherally to the gastroduodenal tributary.

In the present communication four non-cirrhotic patients are described, who, during surgery, had the hepatic arterial blood supply interrupted during peripheral ligation of the hepatic artery. Only slight and transient symptoms of liver damage were demonstrated in the post-operative period in these four cases.

\section{CASE REPORTS}

CASE 1 A woman of 64 with symptoms for four years of biliary tract disease underwent a cholecystectomy and choledochotomy. The immediate post-operative course was uneventful, but four weeks after the operation she had a severe haematemesis and was admitted to this hospital. On examination an oesophageal hiatal hernia, a slightly deformed duodenal bulb, and a diverticulum of the duodenum were found, and, though oesophagoscopy did not reveal any peptic ulcer, the bleeding was thought to be due to the hernia and a transthoracic herniotomy was performed. Two weeks after the second operation she had a second severe haematemesis and a further operation was necessary, this time a bleeding duodenal ulcer being suspected.

At operation, however, no abnormality was found in the ventricle and duodenum, but during duodenotomy it was observed that the bleeding originated in the deep biliary tracts as pulsating bleeding through the papilla of Vater was seen. By choledochotomy near the cystic duct it was seen that the bleeding came from the hepatic duct. As immediate haemostasis was vital at that stage of the operation the hepatic artery was ligated distal to the pancreatic-duodenal artery after which the bleeding quickly stopped.

After the operation penicillin $(2 \mathrm{~m}$. units twice daily) and streptomycin ( $1 \mathrm{~g}$. daily) were given for 11 days.

On the third post-operative day the serum transaminases showed slightly raised values: glutamic-oxalic acid transaminase (S-GOT) 2.8 units (normal < 1.7), glutamic-pyruvic acid transaminase (S-GPT) 5.5 units (normal $<1.5$ ) but on the twelfth day after the operation all values were normal. Serum bilirubin, thymol turbidity, and alkaline phosphatases were normal postoperatively and paper electrophoresis showed the following values: Albumin 1.97, alpha 0.70 , alpha 2.94 , beta 0.57 , beta ${ }_{2} 0.43$, and gamma globulin $1.30 \mathrm{~g} . / 100 \mathrm{ml}$.

The patient left the hospital well 32 days after the last operation.

She was readmitted 13 months later on account of a ventral hernia. She had been completely well since the ligation of the hepatic artery and had no episodes of bleeding. At the subsequent herniotomy the liver was inspected. It was macroscopically normal and a liver biopsy from the edge showed very moderate changes, slight fatty degeneration, moderate portal infiltration and fibrosis (Fig. 1). Liver function tests were all normal. Bromsulphalein retention $(5 \mathrm{mg}$. $/ \mathrm{kg}$. body weight, $45 \mathrm{~min}$. retention) was $2 \%$. Abdominal aortography showed normal filling of the coeliac, gastric, and splenic arteries but no filling of the hepatic artery.

CASE 2 A girl of 8 months was admitted very ill with a greatly enlarged liver. At laparotomy a large tumour occupying four fifths of the liver substance was found. Fresh blood was aspirated from the tumour but no biopsy could be taken because of bleeding. The tumour was thought to be a haemangioma with no possibility of extirpation:

Six months later the liver was further enlarged and the general condition of the child was extremely bad. It was decided to ligate the hepatic artery hoping that this 


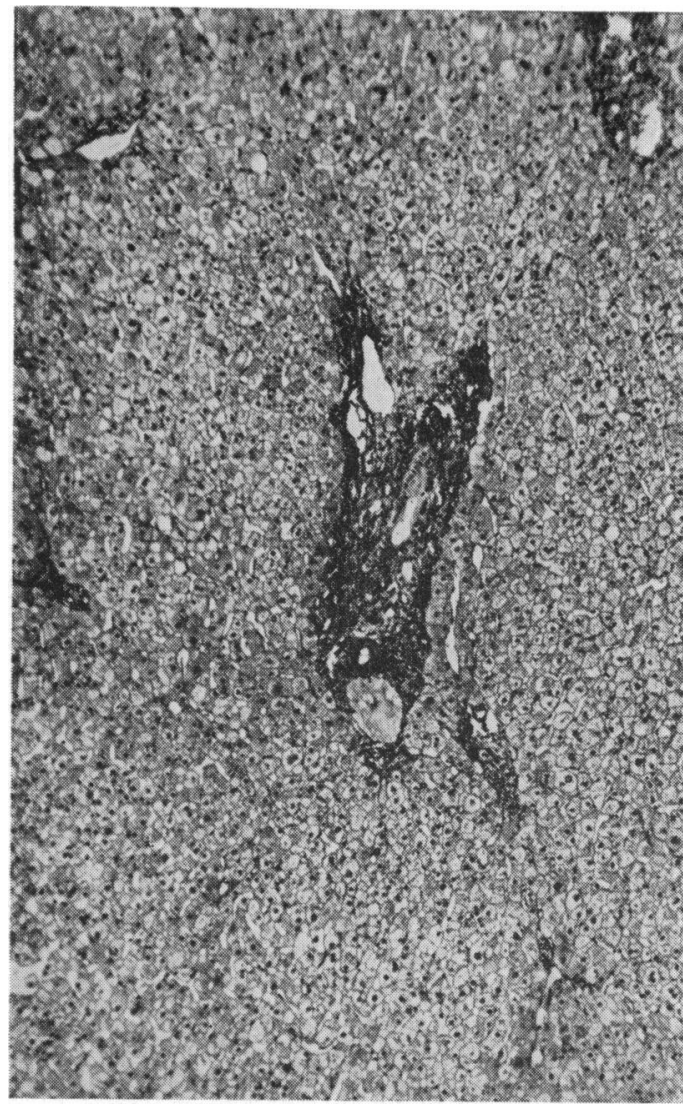

FIG. 1 (Case 1). Liver biopsy 13 months after ligation of the hepatic artery.

procedure would shrink the haemangioma so making a later extirpation possible. At operation the hepatic artery proper was $4 \mathrm{~mm}$. in diameter and the portal vein normal. There was no evidence of dilated veins in the portal tract. Immediately after the ligation of the artery the tumour was seen to shrink. Post-operatively the patient was treated with penicillin $(0.5 \mathrm{~m}$. units twice daily).

Pre-operative liver function tests had been normal (S-GOT 2 units, thymol turbidity 0.11 units (normal $<0.15$ ), prothrombin $100 \%$ ). After the ligation of the hepatic artery an important but short-lasting rise in the transaminase values (maximally 186 units) was seen, returning to normal values in 12 days. Post-operatively the thymol reaction was $0 \cdot 21$ and the serum bilirubin level $2.0 \mathrm{mg}$. $/ 100 \mathrm{ml}$., falling to $0.6 \mathrm{mg}$. $/ 100 \mathrm{ml}$. The patient was discharged 19 days after the operation.

She was readmitted three months later greatly deteriorated. Liver function tests were only slightly abnormal (serum bilirubin $1.0 \mathrm{mg} . / 100 \mathrm{ml}$, , thymol 0.17 , prothrombin $165 \%$ ). Paper electrophoresis showed: Albumin $4 \cdot 3, a_{1} 0 \cdot 78, a_{2} 0 \cdot 82, \beta_{1} 0 \cdot 59, \beta_{2} 0 \cdot 45$, and gamma globulin $0.94 \mathrm{mg} . / 100 \mathrm{ml}$.

Though it was thought impossible to improve the patient's condition a second laparotomy was performed at the urgent request of the parents, but during the operation the heart stopped and death followed. The hepatic artery distal to the earlier place of ligation was obliterated. The liver was half the size observed during the previous operation. Microscopy from the tumour showed liver cell carcinoma and from the macroscopically normal liver tissue no pathological changes apart from slight periportal infiltration were seen.

CASE 3 A man of 73 was admitted for reconstruction of the bile ducts on account of a lesion of the choledochus resulting from a choledochotomy 10 months previously.

During the operation the choledochus and the hepatic duct were found to be imbedded in a great amount of cicatricial tissue reaching from the porta hepatis to the duodenum. When the dissection was completed only the portal vein was seen to be intact. The common hepatic and the pancreatic-duodenal arteries were localized but the hepatic artery proper was lost in the scar tissue and no arterial branches could be seen in the porta hepatis. The liver was enlarged with pronounced gall stasis. A Roux anastomosis was made to the right hepatic duct. The post-operative course was complicated by a subphrenic abscess but at discharge four months later the patient was well.

Liver function tests pre-operatively showed signs of occlusive jaundice with a serum bilirubin level of 11.9 $\mathrm{mg} . / 100 \mathrm{ml}$, , raised alkaline phosphatases and normal thymol turbidity and serum electrophoresis. After the operation the serum bilirubin level fell to $1.5 \mathrm{mg}$. $/ 100 \mathrm{ml}$.

CASE 4 A man of 53 was admitted on account of gastric carcinoma.

During the operation a large tumour in the fundus with invasion in the tail of the pancreas was found. In the coeliac lymph nodes metastases were present and some of these were invading the wall of the vessels. Hard lymph nodes were found along the hepatic artery but none in the porta hepatis. It was thought possible to remove the tumour macroscopically by total gastrectomy and resecting the tail of the pancreas and the coeliac artery with its three branches.

The stomach was removed from the cardia to $2 \mathrm{~cm}$. distal to the pylorus together with the great omentum and the tail of the pancreas. The coeliac artery was ligated near the aorta and removed with the left gastric and splenic arteries. The hepatic artery was laid free throughout its course and removed after ligation of the pancreatic-duodenal artery and the two branches of the hepatic artery proper in the porta hepatis. A cholecystectomy was performed simultaneously.

Post-operatively the patient received penicillin $(2 \mathrm{~m}$. units twice daily for 14 days). An intestinal fistula closed spontaneously in the course of a month.

Results of post-operative liver function tests are shown in Table I. Fourteen days after the operation serum electrophoresis was normal apart from slightly decreased serum albumin $(3.6 \mathrm{~g}$. $/ 100 \mathrm{ml}$.). The patient was discharged two months after the operation.

Five months later the patient was readmitted for observation. His general state was good and there were no clinical signs of metastases. Some time before this 


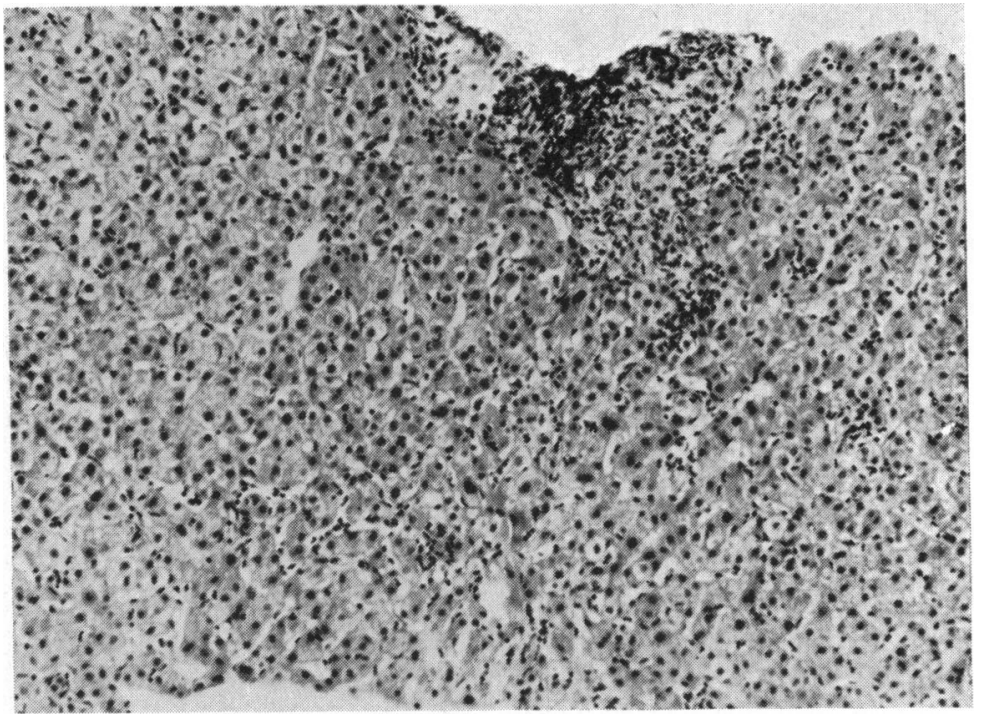

FIG. 2

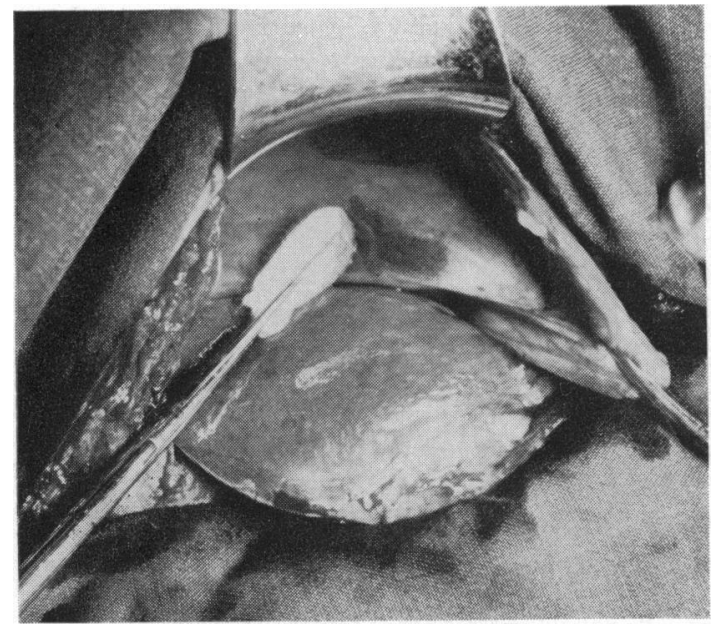

FIG. 3

FIG. 2 (Case 4). Liver biopsy five months after ligation of the hepatic artery.

FIG. 3 (Case 4). Liver at laparotomy 10 months after ligation of the hepatic artery.

FIG. 4 (Case 4). Liver biopsy 10 months after ligation of the hepatic artery.

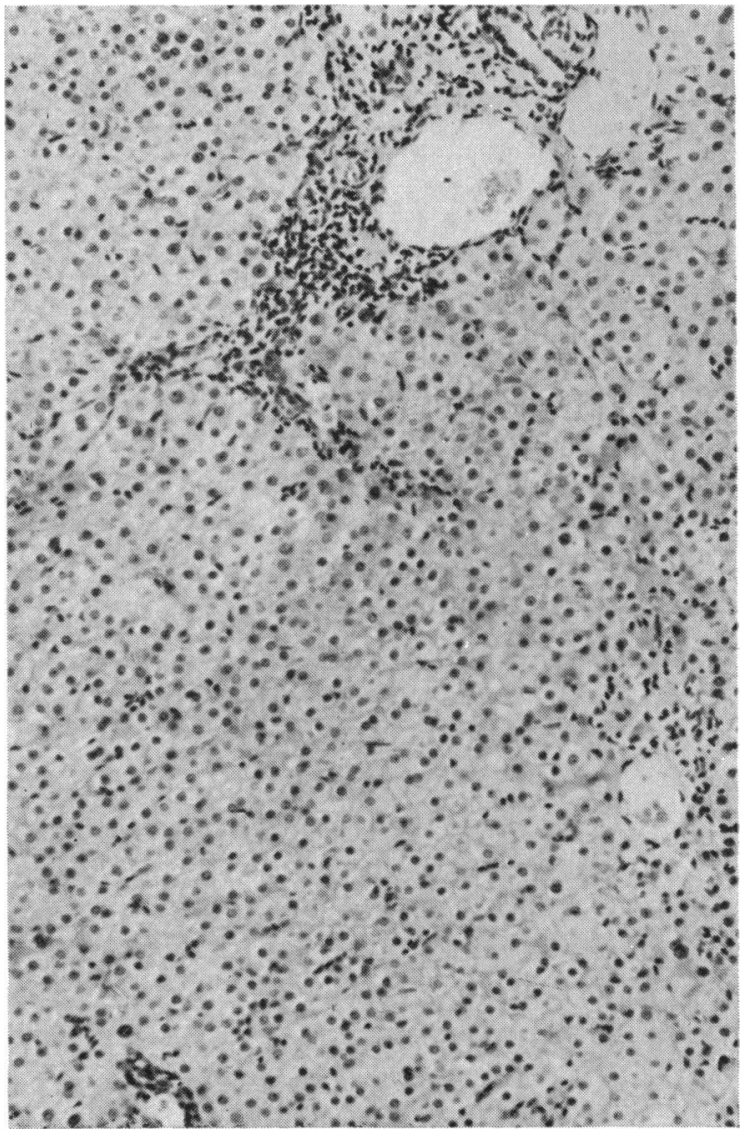


TABLE I

RESULTS OF LIVER FUNCTION TESTS IN CASE 4

\begin{tabular}{|c|c|c|c|c|c|c|}
\hline Days after operation & 2 & 5 & 8 & 16 & 24 & 42 \\
\hline S-GOT (units) & $7 \cdot 0$ & $16 \cdot 0$ & $6 \cdot 7$ & $4 \cdot 6$ & 1.6 & 1.6 \\
\hline S-GPT (units) & $19 \cdot 5$ & $13 \cdot 1$ & 4.9 & $3 \cdot 5$ & 1.4 & $1 \cdot 1$ \\
\hline $\begin{array}{l}\text { Thymol (extinction } \\
\text { units) }\end{array}$ & & & & & 0.05 & 0.03 \\
\hline Prothrombin (\%) & & 46 & 70 & 80 & & 78 \\
\hline $\begin{array}{l}\text { Serum bilirubin } \\
\text { (mg./100 ml.) }\end{array}$ & $3 \cdot 5$ & $2 \cdot 3$ & & $1 \cdot 1$ & & $1 \cdot 6$ \\
\hline $\begin{array}{l}\text { Alkaline phosphatase } \\
\text { (units) }\end{array}$ & & $6 \cdot 8$ & 6.0 & & $1 \cdot 2$ & \\
\hline
\end{tabular}

admission the patient suffered jaundice and itching. The liver function tests showed signs of parenchymatous liver damage but improved during the patient's stay in hospital. After the jaundice had disappeared a percutaneous liver biopsy was done. It showed (Fig. 2) slight periportal infiltration and old bile pigment in the cells, so the episode of jaundice and itching was probably due to an acute viral hepatitis.

The patient was seen in the department 10 months after the operation. He suffered from general fatigue and loss of weight. Liver function tests (S-GOT, S-GPT, thymol, serum electrophoresis) were normal; the serum bilirubin level was $1.8 \mathrm{mg}$. $/ 100 \mathrm{ml}$. Intravenous cholangiography showed a dilated choledochus and an explorative laparotomy was performed. No signs of tumour and metastases were found and the choledochus was not obstructed. The liver was normal macroscopically (Fig. 3) as well as microscopically (Fig. 4).

Post-operatively the liver function tests were normal. The serum bilirubin level was $0.8 \mathrm{mg} . / 100 \mathrm{ml}$. and the bromsulphalein retention test $8.8 \%$. The patient was discharged in good condition and had gained considerably in weight.

\section{DISCUSSION}

The four cases cited show that it has been possible to ligate the hepatic artery near the porta hepatis without greater or lasting damage to the hepatic parenchyma. In the three patients in whom laboratory examinations in relation to the ligation were available short-lived signs of liver necrosis were present. In Case 1 normal liver function and only minute changes in the liver biopsy were found 13 months after the operation. Case 2 displayed no signs of altered liver function three months after the ligation but died from the malignant liver tumour. The third patient, in whom the hepatic artery presumably was ligated inadvertently during the operation 10 months before the patient was seen here, only showed biochemical evidence of disturbed liver function which could be ascribed to the extrahepatic occlusive jaundice. In the fourth case an episode of signs of parenchymal liver damage was probably due to a viral hepatitis and at a subsequent admission 10 months after the operation the liver was normal.

In the literature many animal experiments have been described devoted to the effect of ligation of the hepatic artery (e.g., Cameron and Mayes, 1930, including references to papers from 1640 to 1930). It is, however, difficult from animal experiments to draw any definite conclusions regarding the effect in humans as the variability within species is great. Thus, while dogs almost always die after ligation of the hepatic artery (Rappaport, 1951), most monkeys survive (Child, 1954) and rats may even regenerate liver tissue after hepatic resection preceded by ligation of the hepatic artery (Wiles, Schenk, and Lindenberg, 1952).

In humans the arterial blood supply to the liver has been interrupted for several reasons-accidentally, spontaneously (thrombosis and tumours), deliberately (aneurysms of the hepatic artery, Käding, 1919), and by severe haemorrhage from the artery. The first surviving case in man is described by Kehr (1903), who ligated the hepatic artery proper for an aneurysm. The patient survived without aftereffects but during the post-operative period liver necrosis and discharge of necrotic liver tissue was seen through the operation wound. An early surviving case is that of von Hofmeister (1922), and Holst (1920) and Behrend (1920) reported one case each with death on account of gross liver necrosis. In the survey of Graham and Cannell (1933) from the literature 28 cases with interruption of the hepatic artery were found with 16 deaths, at least seven of these due to liver failure. In this survey cases with ligation proximal to the gastroduodenal artery are included, a procedure which is much better tolerated as the liver is then supplied by that artery, as shown in animal experiments by Haberer (1905).

The cause of the damaging effect of hepatic arterial ligation is regarded as anoxia of the liver caused by interruption of the artery which is probably responsible for about $50 \%$ of hepatic oxygen consumption. Liver necrosis follows and in some cases gas-producing bacteria are found. Markowitz, Rappaport, and Scott (1949) underlined the importance of the last-mentioned point when they found that it was possible by post-operative treatment with penicillin to protect almost all dogs from death after ligation of the hepatic artery. Rappaport (1951), however, is of the opinion that death in man is caused by aseptic anoxic liver necrosis.

The explanation of the differences in reaction towards hepatic arterial ligation in species is probbably to be found in the different number of arterial anastomoses to the liver, i.e., through the phrenic artery and the falciform ligament, though these anastomoses often have been difficult to demonstrate 
in animals surviving the ligation (Tanturi, Swigart, and Canepa, 1950). Popper, Jefferson, Hassan, Phillips, Proffitt, and Necheles (1955) have shown by plugging the intrahepatic arterial twigs with a plastic substance that this procedure was always followed by death, so that the intrahepatic arterial network is presumably of vital importance.

The importance of the possibility of ligating the hepatic artery is demonstrated in the four case reports, specially Case 4 . It is, however, in our opinion not possible from these few cases to consider peripheral ligation of the hepatic artery as a procedure without risk. The fatal outcome of cases cited in the literature is probably independent of antibiotic therapy but depends on the amount of arterial blood reaching the liver by other routes (anatomical variants) than through the ligated artery. A very grave indication must exist before interruption of the hepatic arterial blood supply is considered.

If further investigations can prove that the liver can dispense with its arterial blood supply the procedure mentioned might be helpful in operation for gastric carcinoma, where a resection of the coeliac artery with its three branches and surrounding lymph nodes would make the operation more radical in suitable cases.

\section{REFERENCES}

Behrend, M. (1920). Experimental ligation of the hepatic artery. Surg. Gynec. Obstet., 31, 182-183.

Cameron, G. R., and Mayes, B. T. (1930). Ligation of the hepatic artery. J. Path. Bact., 33, 799-831.

Child, C. G. (1954). The Hepatic Circulation and Portal Hypertension, p. 196. Saunders, Philadelphia.

Graham, R. R., and Cannell, D. (1933). Accidental ligation of the hepatic artery. Brit. J. Surg., 20, 566-579.

Haberer, H. (1905). Experimentelle Unterbindung der Leberarterie. Arch. klin. Chir., 78, 557-587.

Hofmeister, F. von (1922). Unterbindung der Arteria hepatica propria ohne Leberschädigung. Zbl. Chir., 49, 154-157.

Holst, S. F. (1920). Underbinding av art. hepatica propria. Norsk Mag. Lagevidensk., 81, 1182-1193.

Kăding, K. (1919). Ein geheilter Fall von intrahepatischem Aneurysma mit besonderer Berücksichtigung der traumatischen Leberarterienaneurysmen. Dtsch. Z. Chir., 150, 82-104.

Kehr, H. (1903). Der erste Fall von erfolgreicher Unterbindung der Art. hepatica propria wegen Aneurysma. Münch. med. Wschr. 50, $1861-1867$.

Markowitz, J., Rappaport, A., and Scott, A. C. (1949). Prevention of liver necrosis following ligation of hepatic artery. Proc. Soc. exp. Biol. (N.Y.), 70, 305

Popper, H. L., Jefferson, N. C., Hassan, M. I., Phillips, C. W., Proffitt, M. M., and Necheles, H. (1955). Interference with the intrahepatic blood circulation. Amer. J. Physiol. 183, 235-236.

Rappaport, A. M. (1951). Experimental ischemia of the liver and hepatic coma. In Liver Injury, Trans. 10th Conference, pp. 146180. Josiah Macy, Jr. Foundation, N.Y.

Tanturi, C., Swigart, L. L., and Canepa, J. F. (1950). Prevention of death from experimental ligation of the liver (hepatic proper) branches of the hepatic artery. Surg. Gynec. Obstet., 91, 680704.

Wiles, C. E., Schenk, W. G., and Lindenberg, J. (1952). Influence of hepatic artery ligation on regeneration of liver tissue in the rat. A.M.A. Arch. Surg., 64, 783-787. 